\title{
On the Results of the First All-Russian Conference "Sol-Gel Synthesis and Study of Inorganic Compounds, Hybrid Functional Materials, and Disperse Systems"
}

DOI: $10.1134 / \mathrm{S} 1087659611020167$

The First All-Russian Conference "Sol-Gel Synthesis and Study of Inorganic Compounds, Hybrid Functional Materials, and Disperse Systems" ("SolGel-2010") devoted to a single method of liquidphase synthesis, i.e., sol-gel synthesis, was held on November 22-24, 2010 in St. Petersburg. As was noted by the chairman of the conference, Academician V.Ya. Shevchenko in his opening speech, "From the times of the ancient inorganic chemistry and alchemy, the sol-gel reaction provides the basis of the best methods used in preparing new inorganic substances, and this reaction has opened up the way to advanced nanotechnologies." Probably, that is why the leading scientists of Russia, Belarus, and Ukraine, who have engaged in the field of sol-gel synthesis, responded to the call of the Grebenshchikov Institute of Silicate Chemistry of the Russian Academy of Sciences, which organized this conference. More than 200 applications were received for the participation in the First All-Russian conference "Sol-Gel 2010." The geography of the authors of the published theses has impressed: Apatity, Asbest, Belgorod, Vladivostok, Voronezh, Gatchina, Gomel, Dnepropetrovsk, Donetsk, Egor'evsk, Yekaterinburg, Ivanovo, Ivano-Frankovsk, Izhevsk, Zelenograd, Kiev, Kirov, Krasnoyarsk, Magnitogorsk, Minsk, Moscow, Nizhni Novgorod, Novosibirsk, Perm, Petrozavodsk, St. Petersburg, Snezhinsk, Syktyvkar, Taganrog, Tambov, Tomsk, Ufa, Kharkov, and Chernogolovka, including their coauthors from Germany, China, Poland, and France. Altogether, 140 participants directly took part in the conference. The past conference was rather representative: it involved a number of highly skilled specialists: two academicians of the Russian Academy of Sciences, three corresponding members of the Russian Academy of Sciences, 22 doctors of sciences, and 47 candidates of sciences $(\mathrm{PhD})$. At the same time, young scientists amounted to $50 \%$ of the participants of the conference. The high level of reports, the friendly creative atmosphere, and the interest expressed by the participants in the development of the sol-gel direction are worthy of notice. All reports presented at the conference were distributed over four sections: (1) hybrid inorganic and organic-inorganic sol-gel materials; (2) sol-gel synthesis and study of nanoparticles; (3) sol-gel films, coatings, and membranes; and (4) xerogels, glasses, and bulk ceramic materials synthesized by the sol-gel method.

The round table devoted to the problem of training of specialists in the field of synthesis and investigation of microcomposite and nanocomposite inorganic and hybrid functional materials was organized in the framework of the conference. The representatives of the St. Petersburg State Electrotechnical University "LETI" and the St. Petersburg State University, i.e., the higher education institutions, which are leading in a number of directions that are directly associated with the sol-gel technology, spoke at this round table. The developed discussion indicated the importance of the problems considered by the participants.

The competition of the best works of young scientists was performed in the framework of the poster session of the conference. Six young scientists, representatives of academic institutes and higher education institutes from Moscow, St. Petersburg, Gomel, Kiev, Syktyvkar, and Tomsk, became winners of the competition and received prizes and diplomas of the conference. Numerous positive opinions of participants have strengthened our assurance that the conference under the guidance of the Grebenshchikov Institute of Silicate Chemistry of the Russian Academy of Sciences will become a traditional All-Russian scientific meeting with international participants and the next meeting of concerned specialists will take place in 2012.

The conference program is presented at the website of the Grebenshchikov Institute of Silicate Chemistry of the Russian Academy of Sciences (http://www.isc.nw.ru/Rus/conference.htm). 